\title{
A Mixed Digital / Physical Snapshot of Early Internet / Web Usage in New Zealand
}

\author{
Sally Jo Cunningham \\ Computer Science Dept \\ University of Waikato \\ Hamilton, New Zealand \\ +6478384402 \\ sallyjo@cs.waikato.ac.nz
}

\begin{abstract}
We are in the early stages of developing a unique physical and digital record of New Zealand's early experience of the Internet.
\end{abstract}

\section{Categories and Subject Descriptors}

H.3.7 [Digital Libraries]: Collection

\section{General Terms}

Documentation, Design

\section{Keywords}

Internet Archive, Digital Museum, History of the Web

\section{INTRODUCTION}

Internet archives have been created as permanent records of the Web and other Internet documents. The Internet Archive (www.archive.org) - a collection of general Web pages - is the best known, but national collections (eg, Australia, pandora.nla.gov.au; Sweden, kulturarw3.kb.se) also exist. These archives capture the raw material of the Web, but cannot record usage [1]: which resources the Internet denizens of that moment found most useful or compelling, how the resources were accessed, how they were shared within a community, etc.

For New Zealand, a partial record of Internet / WWW usage from the early 1990s still exists; though the Web logs and Internet traffic records from that time are long gone, paper records remain from those early heady days. For years the entire country was dependent on a single Internet feed through Waikato University (Hamilton) [2]. In the early 1990s, Waikato University staff were also looked to as experts in accessing and using these new resources. Connection speeds were painfully slow and terminals were scarce, so University Library reference staff created paper records of useful internet documents (Figure 1). This dusty filing cabinet contains the only records of Internet usage in New Zealand when the Internet and WWW were introduced. These documents will be the core of a physical and digital archive of New Zealand's early Internet experiences.

Copyright is held by the author/owner(s).

JCDL'09, June 15-19, 2009, Austin, Texas, USA.

ACM 978-1-60558-322-8/09/06.

\author{
Jillene Bydder \\ Library \\ University of Waikato \\ Hamilton, New Zealand \\ +6478384402 \\ jbydder@waikato.ac.nz
}

\section{COLLECTION DOCUMENTS}

The papers in the filing cabinet include printouts of 'how to use the Internet' guides, instructions for using access software, lists of interesting Websites, and so forth. Many of the printouts are annotated (eg, "didn't get all of this - too big!", for a massive $301 \mathrm{k}$ text file). Other records include early Internet humor (eg, cartoons), commercially printed books, and copies of webpages. These will form the core of our collection. We are also planning to augment these records with interviews with early New Zealand Internet / Web adopters.

\section{PHYSICAL / DIGITAL PRESENTATION}

We are preserving the physical documents in a local display at Waikato University. These documents will be scanned and presented in a parallel digital collection; scanning is necessary to present the annotations as well as to preserve the appearance of the line printed, Courier font originals. Some of these documents no longer exist elsewhere on the Internet, and so our collection will support other preservation efforts. Astonishingly, this digital collection will make a primary New Zealand Internet guide from this period available digitally for the first time - connection costs were so high at the time that it was cheaper to print and mail it!

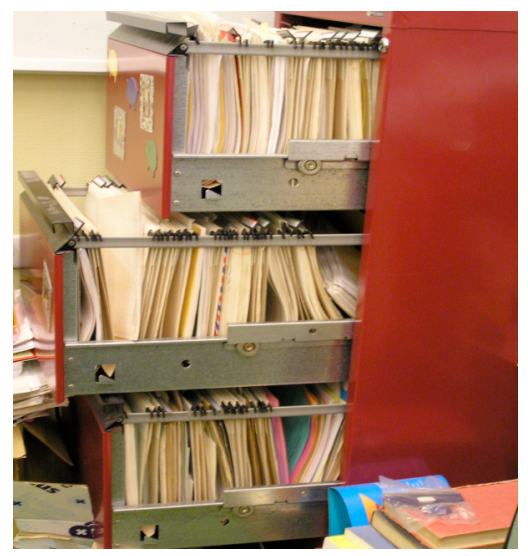

Fig 1. NZ's view of the Internet / WWW, early 1990s

\section{REFERENCES}

[1] Kahle, B. 1997. Preserving the Internet. Scientific American 276(3), 82

[2] Newman, K. 2008. Connecting the Clouds: The Internet in New Zealand. Activity Press. 